\title{
DILATOMETRIC CHARACTERIZATION OF PEARLITE DISSOLUTION IN 0.1C-0.5Mn LOW CARBON LOW MANGANESE STEEL.
}

\author{
C. García de Andrés, F. G. Caballero and C. Capdevila \\ Department of Physical Metallurgy \\ Centro Nacional de Investigaciones Metalúrgicas (CENIM) \\ Consejo Superior de Investigaciones Científicas (CSIC) \\ Avda. Gregorio del Amo, 8. 28040 Madrid, Spain
}

\section{Introduction}

Dual-Phase steels, widely used in the automobile industry, are characterized by a superior combination of mechanical properties. These steels are produced by annealing low-carbon steels in the intercritical temperature range with the aim of obtaining ferrite-austenite mixtures, and subsequent quenching to transform the austenite phase into martensite (1-3). They have demonstrated that a ferrite-martensite microstructure promotes continuous yielding with a rapid rate of work hardening and improved elongation in comparison with a ferritepearlite (4). Speich et al (5) delineated the process of intercritical austenitization in low-carbon steels with a ferrite-pearlite starting microstructure in three stages: a) very rapid growth of austenite into pearlite, b) slower growth of austenite into ferrite, and c) slow equilibration of ferrite and austenite. The first step consists of pearlite dissolution and growth of austenite into pearlite at a rate controlled primarily by carbon diffusion in the austenite. In this step, the growth rate of the austenite will be extremely rapid (5-7). García and DeArdo (4) pointed out that before dissolution of pearlite, the lamellar cementite particles spheroidize and the carbon from the cementite particles diffuses toward the growing austenite.

Very little information is avalaible about the austenite formation in steels subjected to continuous heating. In the present work, high-resolution dilatometry was used to study the dissolution of pearlite during continuous heating austenitization in a low-carbon low-manganese steel with a ferrite-pearlite starting microstructure. A clear differentiation between pearlite dissolution process and $\alpha \rightarrow \gamma$ transformation has been found in this steel by means of dilatometric analysis. Moreover, the temperature range of pearlite dissolution process has been determined allowing to select the most suitable intercritical temperature to obtain dual phase microstructures with optimum combination of mechanical properties. The influence of the pearlite morphology on dissolution process has been also studied in this work.

\section{$\underline{\text { Materials and Experimental Procedures }}$}

The chemical composition of the steel studied is presented in Table 1. Semi rolled slabs $36 \mathrm{~mm}$ thick were soaked at $1250^{\circ} \mathrm{C}$ for $15 \mathrm{~min}$., hot rolled to $6 \mathrm{~mm}$ in several passes, and finally air cooled to room temperature. Specimens were machined from this material and named 'Finished Hot-Rolled (FHR)'. Another group of specimens was directly machined from the semi rolled slabs $36 \mathrm{~mm}$ thick, and it is referred below as 'Semi HotRolled (SHR)'. As-rolled resultant microstructures both are formed by $84 \%$ of ferrite and $16 \%$ of pearlite (Fig. 1). As shown below, the interlamellar spacing of the pearlite in FHR and SHR specimens is different (Table 2). Some specimens were reheated to $1000^{\circ} \mathrm{C}$, held for 60 seconds and cooled at cooling rates of $0.05{ }^{\circ} \mathrm{C} / \mathrm{s}, 0.1^{\circ} \mathrm{C} / \mathrm{s}$ and $0.5^{\circ} \mathrm{C} / \mathrm{s}$ to obtain three different morphologies of pearlite in the starting microstructures (ANN1 $\rightarrow 3$ ). The interlamellar spacings of pearlite in these as-annealed microstructure are also listed in Table 2.

TABLE 1

Chemical Composition of low carbon low manganese steel (Mass \%)

\begin{tabular}{|ccccc|}
\hline $\mathrm{C}$ & $\mathrm{Mn}$ & $\mathrm{Si}$ & $\mathrm{Cr}$ & $\mathrm{Ni}$ \\
\hline 0.11 & 0.50 & 0.03 & 0.01 & 0.02 \\
\hline
\end{tabular}

Interlamellar spacings of as-rolled and as-annealed microstructures

\begin{tabular}{|cc|}
\hline Specimen & Interlamellar spacing $(\mu \mathrm{m})$ \\
\hline FHR & $0.14 \pm 0.01$ \\
SHR & $0 . .17 \pm 0.04$ \\
ANN1 & $0.18 \pm 0.03$ \\
ANN2 & $0.25 \pm 0.05$ \\
ANN3 & $0.29 \pm 0.06$ \\
\hline
\end{tabular}



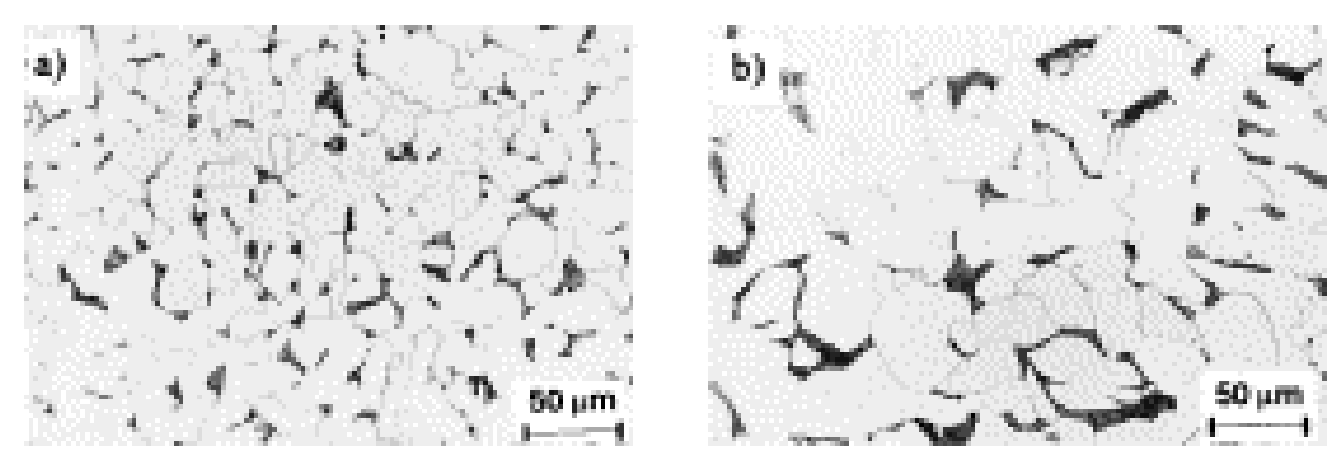

Figure 1. As-rolled microstructures. Etched in $2 \%$ Nital ( $2 \mathrm{~mL}$ nitric acid $+100 \mathrm{~mL}$ propan-2-ol): (a) FHR and (b) SHR. 
Figure 1. As-rolled microstructures. Etched in 2\% Nital (2 mL nitric acid + $100 \mathrm{~mL}$ propan-2-ol):(a) FHR and (b) SHR.

Specimens were polished in the usual way and finished on $0.5 \mu \mathrm{m}$ diamond paste for metallographic examination. Two types of eatching solution were used: Nital-2pct to reveal the ferrite-pearlite microstructure by light optical microscopy and solution of picric acid in isopropyl alcohol with several drops of Vilella's reagent to disclose the pearlite morphology on a Jeol JXA 840 scanning electron microscope. Fig. 2 shows the scanning micrograph of the five different morphologies of pearlite considered in this study (Table 2). Quantitative metallography to determine the interlamellar spacing of pearlite was done according to Underwood's intersection procedure (8). 

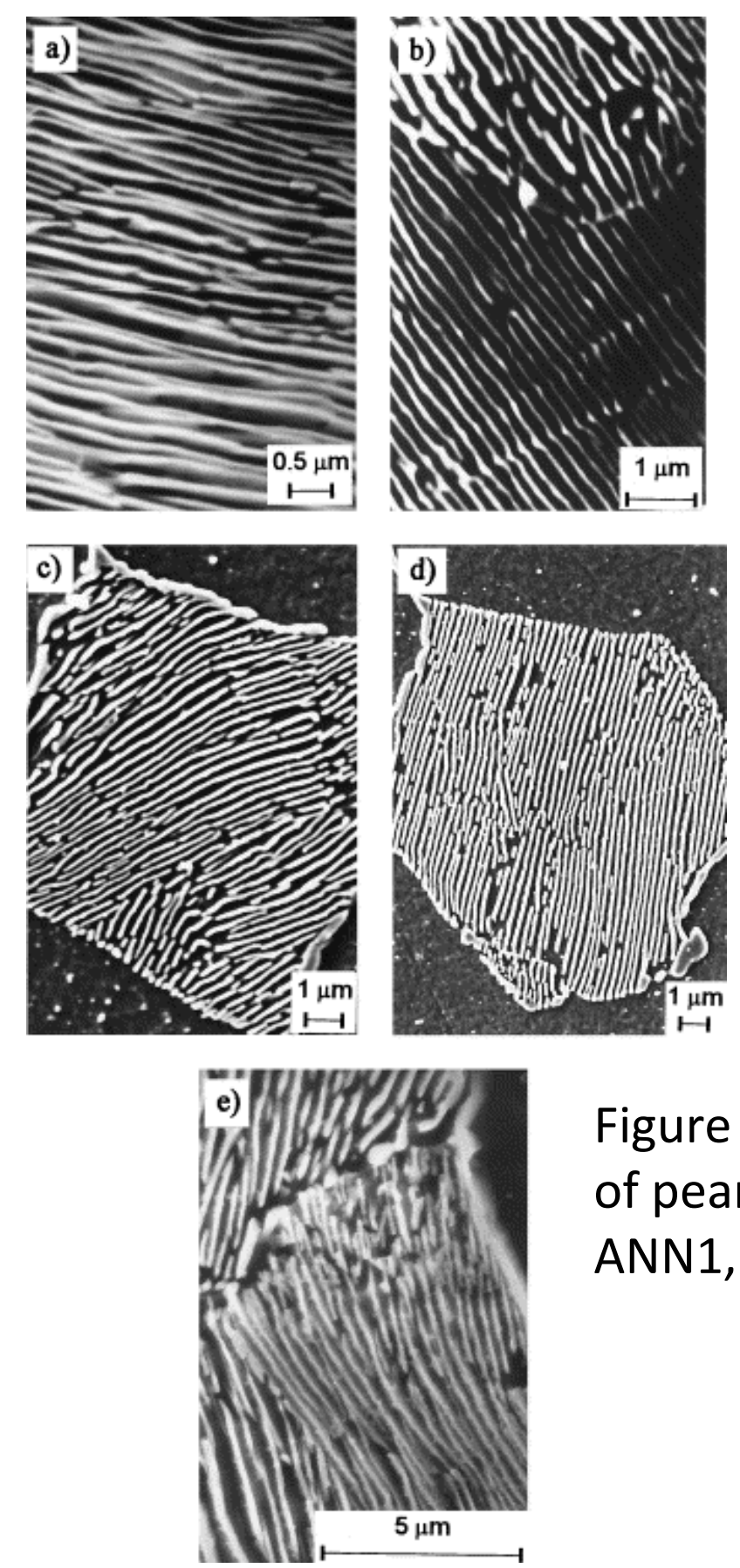

Figure 2. Scanning micrograph of the five different morphologies of pearlite considered in this study (Table 2): (a) FHR, (b) SHR, (c) ANN1, (d) ANN2 and (e) ANN3. 
Figure 2. Scanning micrograph of the five different morphologies of pearlite considered in this study (Table 2): (a) FHR, (b) SHR, (c)ANN1, (d)ANN2 and (e)ANN3.

To study the pearlite dissolution process, dilatometric specimens $2 \mathrm{~mm}$ thick and $12 \mathrm{~mm}$ long with the above mentioned morphologies (Table 2) were heated at a constant rate of $0.05^{\circ} \mathrm{C} / \mathrm{s}$ in a vacuum of $10^{-2} \mathrm{mbar}$. This is the rate normally used for considering quasi-equilibrium conditions (9). For this purpose a Adamel Lhomargy DT1000 high-resolution dilatometer was used.

\section{$\underline{\text { Results and Discussion }}$}

During continuous heating the formation of austenite takes place between the $\mathrm{Ac}_{1}$ and $\mathrm{Ac}_{3}$ temperatures which represent,respectively, the temperature at which the ferrite+pearlite-to-austenite transformation starts and ends (10). The expected variation of the relative change of length as a function of temperature $\left(\left(\Delta \mathrm{L} / \mathrm{L}_{0}\right)=\mathrm{f}(\mathrm{T})\right)$ schematically shown in the dilatometric curve of Fig. 3, reproduces the contraction usually undergone by a steel during the austenite formation in continuous heating. No differentiation between pearlite dissolution process and $\alpha \rightarrow \gamma$ transformation is apparently detected in the dilatometric curve of Fig. 3. However, the experimental heating dilatometric curves for the FHR specimen in Fig. 4 shows an unusual anomaly at the onset of the austenitization. This well formed anomaly is shown as a contraction in principle associated to the pearlite dissolution. Firstly, to confirm that this anomaly effectively corresponds to the pearlite-to-austenite transformation, specimens were heated up to $10^{\circ} \mathrm{C}$ below and above the temperature of the dilatometric peak which corresponds to the anomaly, and immediately quenched at a cooling rate of $500^{\circ} \mathrm{C} / \mathrm{s}$ approx.

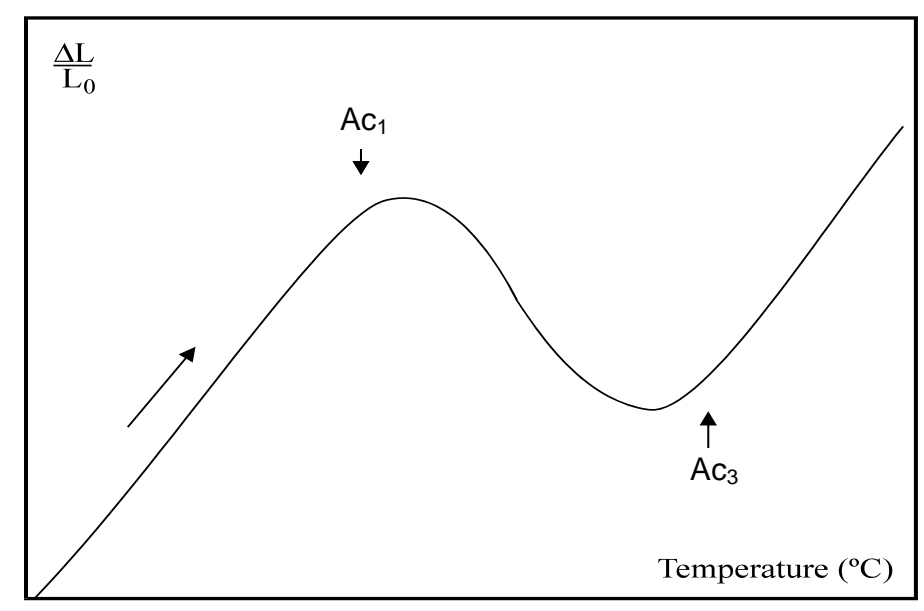

Figure 3. Schematical variation of the relative change of length as a function of temperature during continuous heating

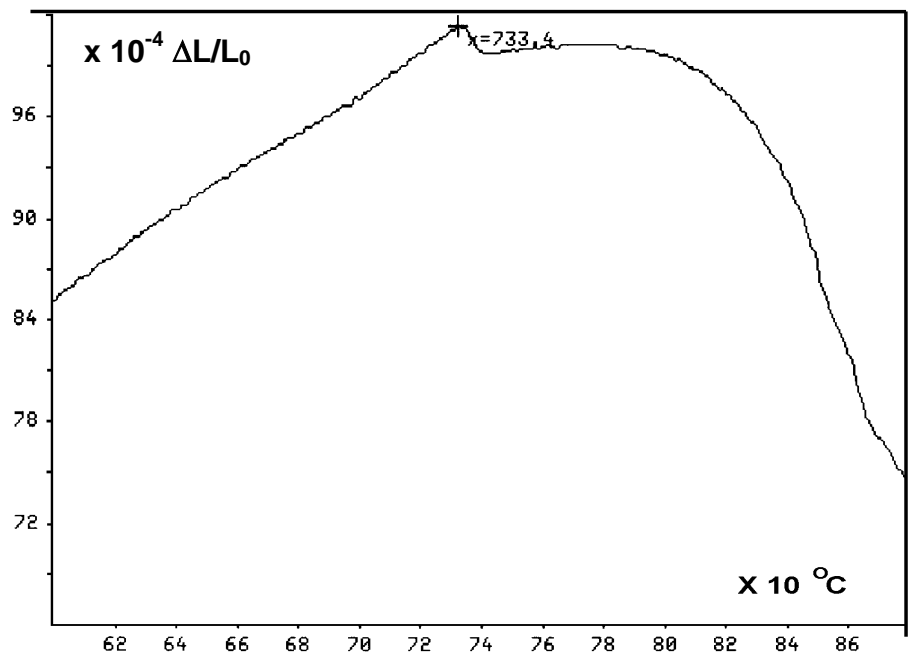

Figure 4. Experimental heating dilatometric curve for FHR specimen

Fig. 5 and 6 show the microstructures obtained in the interrupted heating tests at the above mentioned temperatures. It is clear from the Fig. 5 that no transformation has taken place since the microstructure after this interrupted heating test is formed by ferrite and pearlite and no trace of martensite has been found. However, some martensite areas in Fig. 6 demonstrate that the dissolution of pearlite was taking place during heating at temperatures higher than peak temperature, confirming that this anomaly is clearly associated to that process. A coarsening of the lamellar pearlite morphology in micrographs both of Figure 5 and 6 is observed in comparison with as rolled microstructure in Fig. 2 (a). In some pearlite colonies, a slight spheroidizing of the lamellar cementite before dissolution of pearlite is found (Fig. 5), as it was reported by Garcia and DeArdo (4).

Theoretical studies (11-14) concerning the growth rate of austenite into pearlite concluded that the dissolution process is controlled by the diffusion of carbon in the growing phase, and it was assumed that the effective diffusion distance is aproximately equal to the interlamellar spacing of pearlite. Hillert et al (13) studied the isothermal formation of austenite from a mixture of ferrite and pearlite, and suggested that the expression of the austenite growth rate could have the general form 
where $\mathrm{S}$ is the interlamellar spacing of pearlite. The growth rate of austenite into pearlite decreases as interlamellar spacing increases. On the other hand, a significant influence of the austenite growth rate on the dilatometric anomaly associated to the pearlite-to-austenite transformation is expected and, as it is demonstrated below, high resolution dilatometric technique has been successfully used in this work to study this transformation.

Figure 5. Microstructures obtained in the interrupted heating tests at $10^{\circ} \mathrm{C}$ below $\mathrm{Ac}_{1}$.

When a solid state phase transformation takes place during continuous heating treatment, the relative change of length observed in the dilatometric curve arises from both the thermal expansion and the dimensional changes associated with a phase transformation , so the total relative change of length should be expressed as follows:

$$
\frac{\Delta \mathrm{L}}{\mathrm{L}_{0}}=\left(\frac{\Delta \mathrm{L}_{\mathrm{t}}}{\mathrm{L}_{0}}\right)_{\substack{\text { thermal } \\ \text { expansion }}}+\left(\frac{\Delta \mathrm{L}_{\mathrm{p}}}{\mathrm{L}_{0}}\right)_{\substack{\text { phase } \\ \text { transformation }}}=(\alpha \mathrm{T})_{\substack{\text { thermal } \\ \text { expansion }}}+\left(\frac{\Delta \mathrm{L}_{\mathrm{p}}}{\mathrm{L}_{0}}\right)_{\substack{\text { phase } \\ \text { transformation }}}
$$

where $\left(\Delta \mathrm{L} / \mathrm{L}_{0}\right)$ is the total relative change of length, $\left(\Delta \mathrm{L}_{t} / \mathrm{L}_{0}\right)$ is the relative change of length due to thermal expansion, $\left(\Delta \mathrm{L}_{\mathrm{P}} / \mathrm{L}_{0}\right)$ is the relative change of length due to phase transformation, $\alpha$ is the linear thermal expansion coefficient, and $\mathrm{T}$ is the temperature in centigrade. 


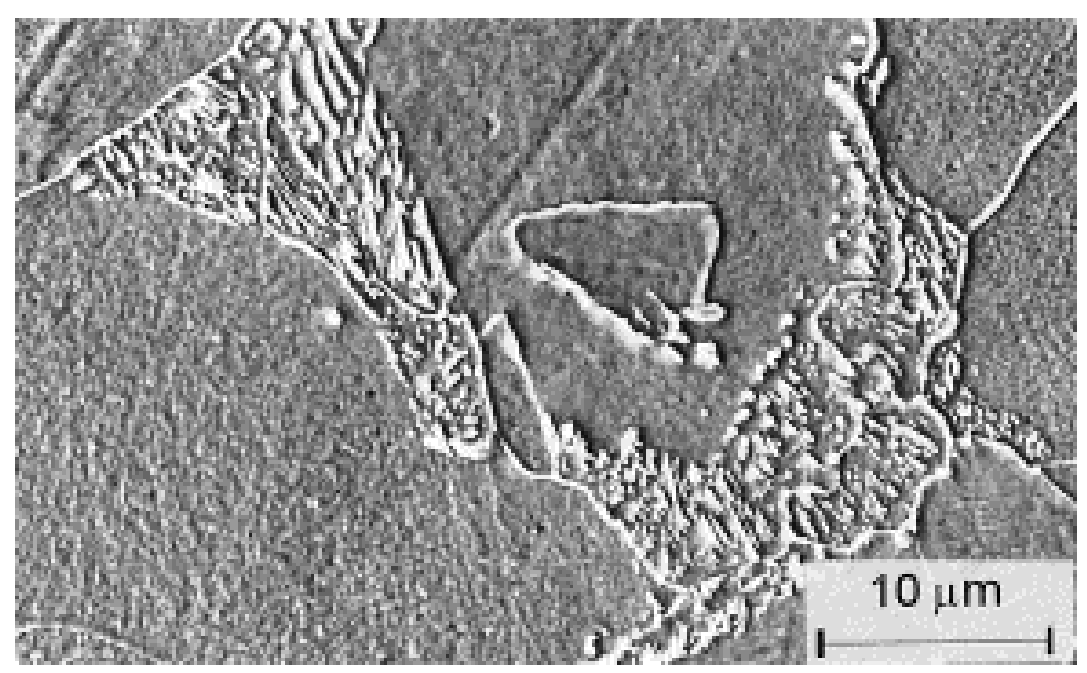

Figure 5. Microstructures obtained in the interrupted heating tests at $10^{\circ} \mathrm{C}$ below $\mathrm{Ac}_{1}$.

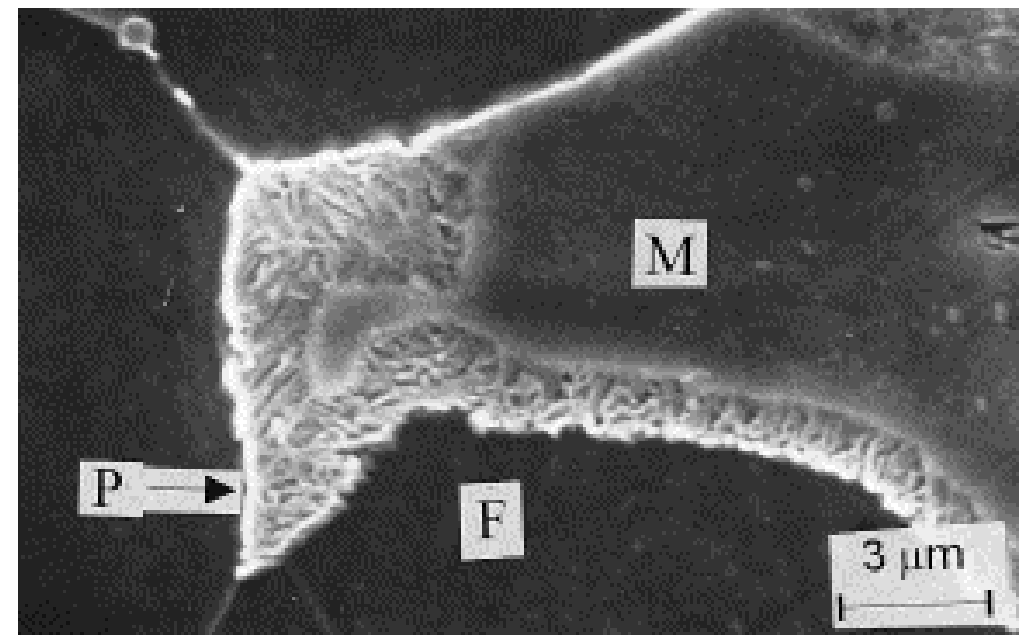

Figure 6. Microstructures obtained in the interrupted heating tests at $10^{\circ} \mathrm{C}$ above $\mathrm{Ac}_{1}$. 
The contribution of thermal expansion in Equation [2] is always positive. However, a contraction occurs during the pearlite-to-austenite transformation. For a given temperature the dimensional change of length due to this transformation has been expressed as follows $(15,16)$,

$$
\frac{\Delta \mathrm{L}_{\mathrm{p}}}{\mathrm{L}_{0}}=\frac{1}{3}\left[\frac{2 \mathrm{a}_{\alpha}^{3}\left(\mathrm{~V}_{\alpha}^{\prime}-\mathrm{V}_{\alpha}\right)+\frac{\mathrm{a}_{\theta}^{3}}{3}\left(\mathrm{~V}_{\theta}^{\prime}-\mathrm{V}_{\theta}\right)+\mathrm{a}_{\gamma}^{3}\left(\mathrm{~V}_{\gamma}^{\prime}-\mathrm{V}_{\gamma}\right)}{2 \mathrm{a}_{\alpha}^{3} \mathrm{~V}_{\alpha}+\frac{\mathrm{a}_{\theta}^{3}}{3} \mathrm{~V}_{\theta}+\mathrm{a}_{\gamma}^{3} \mathrm{~V}_{\gamma}}\right]
$$

where $\mathrm{a}_{\alpha, \gamma, \theta}^{3}$ is the volume of unit cell of ferrite, austenite and cementite respectively at reaction temperature, $\mathrm{V}_{\alpha, \gamma, \theta}$ is the volume fraction of ferrite, austenite and cementite respectively before transformation, and $\mathrm{V}_{\alpha, \gamma, \theta}^{\prime}$ is the volume fraction of ferrite, austenite and cementite respectively after transformation.

In considering the values of volume of unit cells (15-18), it is possible to conclude that the relative change of length associated only to the pearlite-to-austenite transformation during heating from $\mathrm{T}$ to $\mathrm{T}+\Delta \mathrm{T}$ is always negative. As a consequence of this, before the pearlite dissolution occurs the function $\left(\Delta \mathrm{L} / \mathrm{L}_{0}\right)=\mathrm{f}(\mathrm{T})$ shows a linear behaviour with a constant slope. An immediate variation of the slope is observed when the pearlite-toaustenite transformation starts. As transformation progresses, this slope could become negative. Fig. 7 shows the dilatometric curves in quasi-equilibrium heating conditions of the specimens listed in Table 2. We can observe in this figure that the intensity of the pearlite dissolution peak decreases as interlamellar spacing increases coming to dissapear for interlamellar spacing higher than 18 microns. Since very fine pearlite increases the growth rate of austenite into pearlite, this transformation takes place in a narrower temperature range. In Equation [2] the term $\left(\Delta \mathrm{L}_{\mathrm{p}} / \mathrm{L}_{0}\right)$ rises fast and a very sharp contraction peak appears in the dilatometric curve. This dilatometric anomaly allows to identify the pearlite-to-austenite transformation whether fine enough interlamellar spacing is achieved by an appropriate annealing heat treatment.

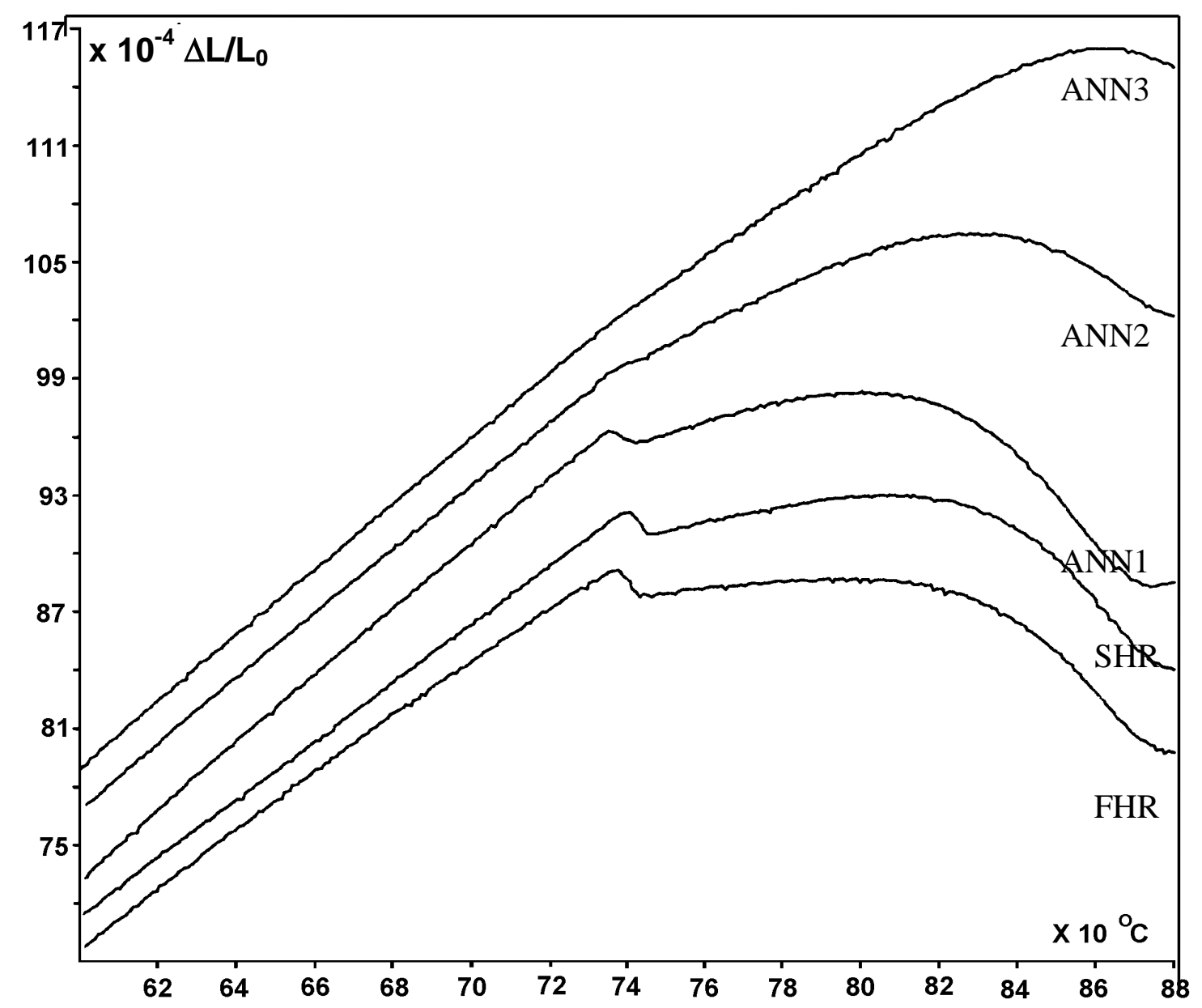

Figure 7. Dilatometric curves in quasi-equilibrium heating conditions of the specimens listed in Table 2 


\section{Conclusions}

1. As a consequence of the wide $\alpha+\gamma$ biphasic field of low carbon steels, a discrimination between the pearlite dissolution process and $\alpha \rightarrow \gamma$ transformation could be expected during continuous heating.

2. A dilatometric anomaly has been observed at the onset of $\alpha \rightarrow \gamma$ transformation in a $0.11 \mathrm{C}-0.5 \mathrm{Mn}$ steel. Interrupted heating tests allowed to demonstrate that this anomaly is associated with the pearlite dissolution process.

3. A significant effect of pearlite interlamellar spacing on the shape of the dilatometric anomaly has been found. This effect is caused by the influence of this morphologic parameter on the austenite growth rate.

4. An accurate dilatometric determination of transformation temperatures corresponding to the pearlite dissolution process in low carbon low manganese steel could be performed when a fine enough pearlite is obtained. The dilatometric anomaly associated with this transformation could be eliminated as pearlite coarses.

5. The possibility of the accurate identification of the finishing temperature of pearlite dissolution process allows to select the most suitable intercritical temperature to obtain dual phase microstructure formed only by ferrite and martensite.

\section{$\underline{\text { Acknowledgements }}$}

The authors acknowledge financial support from the European Coal and Steel Community (ECSC-7210. EC/939) and the Spanish Comisión Interministerial de Ciencia y Tecnología (CICYT-MAT95-1192-CE)

\section{References}

1. G. Krauss, Steels: Heat Treatment and Processing Principles, p. 274, ASM International, Ohio (1989).

2. A. Gustavsson, D. L. Mcdowell, A. Melander, and M. Larsson, Inst. Metallforsk. Forsk. Rapp. 88, 3145 (1994).

3. V. L. Gadgeel, Tool Alloy Steels 28, 17 (1994).

4. C. I. García and A. J. DeArdo, Met. Trans. A 12A, 274 (1981).

5. G. R. Speich, V. A. Demarest and R. L. Miller, Met. Trans. A 12A, 1419 (1981).

6. M. M. Souza, J.R.C. Guimaraes and K. K. Chawla, Met. Trans. A 13A, 575 (1982).

7. Xue-Ling Cai, A. J. Garrat-Reed and W. S. Owen, Met. Trans. A 16A, 543 (1985).

8. E. E. Underwood, Quantitative Stereology, p. 410, Addison-Wesley, Reading (1970).

9. C. García, L. F. Alvarez, M. Carsí, Welding International 6, 612 (1982).

10. C. García De Andres, J. A. Jimenez, and L. F. Alvarez, Met. Trans. A 7A, 1799 (1996).

11. A. Roósz, Z. Gácsi, and E. G. Fuchs, Acta. Metall. 31, 509 (1983).

12. R. R. Judd and H. W. Paxton, TMS-AIME 242, 206 (1968).

13. M. Hillert, K. Nilsson and L.E. Törndahl, J. Iron Steel Inst. 209, 49 (1971).

14. T. Akbay, R. C. Reed, C. Atkinson and M. Enomoto, Proc. Inter. Conf. on Computer Assisted Material Design and Process Simulation (COMMP'93), p. 326, ISIJ, (1983).

15. H.K.D.H. Bhadeshia, Metal Science 16,159 (1982)

16. M. Takahashi, PhD Thesis, University of Cambridge, UK (1992).

17. N. Ridley,H. Stuart and L. Zwel, TMS-AIME 245, 1834 (1962).

18. J. Dyson and B. Holmes, J. Iron Steel Inst. May, 469 (1970). 